\title{
Chemical Resistance of Glass Composite Materials Made From Incinerated Scheduled Waste Slag and SLS Waste Glass
}

\author{
Jariah Mohamad Juoi ${ }^{1, *}$, Dilip Arudra ${ }^{1}$, Zulkifli Mohd Rosli $^{1}$, Khairu Ilwani Karim ${ }^{1}$ and Farah Hanum Suzain ${ }^{1}$ \\ ${ }^{1}$ Advanced Manufacturing Centre, Faculty of Manufacturing Engineering, Universiti Teknikal Malaysia Melaka, 76100 Durian \\ Tunggal, Melaka, Malaysia
}

\begin{abstract}
Incineration of scheduled waste and landfilling of the incineration residue (Bottom Slag) is extensively practised in Malaysia as a treatment method for scheduled waste. Land site disposal of Bottom Slag (BS) may lead to environmental health issues and reduces the availability of land to sustain the nation's development. This research aims in producing Glass Composite Material (GCM) incorporating BS and Soda Lime Silicate (SLS) waste glass as an alternative method for land site disposal and as an effort for recycling SLS waste glass. SLS waste glass originates from the urban waste has been a waste stream in most of the nation whereby the necessity for recycling is in high priority. Batches of powder mixture is formulated with $30 \mathrm{wt} \%$ to $70 \mathrm{wt} \% \%$ of BS powder and SLS waste glass powder for GCM sintering. The powder mixtures of BS and SLS waste glass is compacted by uniaxial pressing and sintered at $800^{\circ} \mathrm{C}$ with heating rate of $2^{\circ} \mathrm{C} / \mathrm{min}$ and 1 hour soaking time into tiles of $18 \mathrm{~mm} \times 18 \mathrm{~mm}$. The GCM porosity and water absorption increases as the BS waste loading increases. Meanwhile, its bulk density increases as the BS waste loading decreases. The GCM tiles made from BS $30 \mathrm{wt} . \%$ and $70 \mathrm{wt}$. \% SLS waste glass are determined to have the lowest water absorption of $1.17 \%$ and porosity percentage of $2.2 \%$ with the highest bulk density of $1.88 \mathrm{~g} / \mathrm{cm}^{3}$. It was also found is found that the chemical resistance of these GCM tiles is classified as ULA (No visible Effect) and UHA (No visible Effect) after 5 day immersions in low and high concentration of acid and alkali solution; respectively (determined using MS ISO1054513:2001(Ceramic Tile: Determination of chemical resistance) test. However, the chemical resistance is weak upon increased duration of 12 immersion days where severe corrosion effects on both surface tiles in low and high concentration chemical solutions. The penetration of chemical in attacking the samples are related to the presence of pores. Hence, further work should have aimed to reduce the amount of porosity presence in the produced tiles.
\end{abstract}

\section{Introduction}

Scheduled waste is defined by The Environmental Quality (Scheduled Waste) Regulations 2005 (amendment 1989) under the Environmental Quality Act 1974 [Act 127] as any waste falls within the 77 categories of hazardous waste listed in the First Schedule [1]. At present, incineration is one of the treatment method for scheduled waste in Malaysia. (Source: Kualiti Alam Sdn.Bhd). Incineration of waste is defined as the controlled burning of a substance whereby controlled refers to clearly defined parameters such as temperature range, oxygen input, turbulence, atmospheric pressure and other aspects of combustion environment. [2]. A waste incinerator typically, consists of a Rotary Kiln (Primary Combustion Chamber) which can incinerate up to $1100^{\circ} \mathrm{C}$ and a secondary combustion chamber which operates more than $1000^{\circ} \mathrm{C}$, meeting the EU incineration requirement (Source: Kualiti Alam Sdn.Bhd). About 13,300 tonnes of bottom slag and tonnes of fly ash are produced annually by incineration [3]. According to the classification of scheduled waste by the Department of Environment Malaysia, incinerated scheduled waste bottom slag falls under the SW501 code whereby the code is defined as any residue from treatment or recovery of scheduled waste [4]. At present, the disposal of bottom slag is done by landfilling.

\footnotetext{
* Corresponding author: jariah@utem.edu.my
} 
The practice of landfilling creates issue of contaminated land whereby land containing substance when present in sufficient concentration, may cause harm to human, animals and environment [5]. Moreover, landfilling does not provide a sustainable solution whereby more land area is required due to increasing waste volume, hence decreases the land availability for nation's development and reducing the land capacity [6]. Utilization of incinerated scheduled waste bottom slag into producing a beneficial product or into a glass composite material would be an effective method in overcoming the inefficiency of current scheduled waste treatment. It reflects advantages in reducing disposal cost, preserving environment, and economic impact [7]. The bottom slag can be classified as a silicate waste due to high content of $\mathrm{SiO}_{2}$. Studies on silicate wastes originated from metallurgic waste incineration, fly ash from coal production, incinerator fly ash and slag from industrial waste, fly ash and slag from municipal solid waste incinerator, incinerated scheduled waste bottom ash has been carried out extensively into producing glass ceramic or glass composite material. Based on this review, there is lack of sufficient work being carried out on incinerated Malaysian scheduled waste bottom slag and this research work highlights on producing glass composite material utilizing this waste $[7,8]$.

Thus, in this work, Malaysian incinerated scheduled waste BS (bottom slag) is incorporated into glass matrix to produce GCM. SLS (soda lime silicate) glass is obtained from urban waste (used glass bottle and household glass containers). Through recycling SLS waste glass, the raw material consumption is reduced yielding economic and environmental benefits [9]. Thus, by incorporating two waste streams (SLS glass and BS), the initiative to promote recycling can be achieved. Glass composite material produced by incorporating industrial waste is a low investment approach and has shown good ability to accommodate desirable properties for the application of floor and roof in industrial and public building, wall covering and road surfacing [10]. The properties of GCM can be tailored based on selection of suitable glass powder, volume fractions, powder processing and firing schedule giving higher possibility to achieve the objective of this research work [11]. It should be highlighted that chemical resistance is an important property for floor and wall covering as tiles are usually subject to chemical aggression as a result of cleaning operations, environmental pollution outdoors and product spill on flooring. Nevertheless, reported work on the chemical resistance of a tile made from waste is limited. Thus, in this paper reports on the evaluation of the chemical resistance of GCM tiles made from BS and SLS waste glass.

\section{Methodology}

Incinerated scheduled waste BS (bottom slag), is obtained from Kualiti Alam Sdn.Bhd situated in Bukit Nanas, Negeri Sembilan. The collected BS was ready to be landfilled. The BS is than pulverized and sieved for a particle size of $<75$ micron. Transparent SLS waste glass (bottles) was obtained from urban waste. The bottles are milled with alumina balls in a milling machine and sieved for particle size of $<75$ micron. The sieved bottom slag (BS) and SLS waste glass powder is then mixed to obtain a mixture of BS and SLS waste glass powder according to weight ratios as shown in Table 1 . Maximizing the BS waste utilization will be an alternative route to reduce the current practice of landfilling BS waste. The waste loading based on weight ratios is selected from $30 \mathrm{wt} \%$ to $70 \mathrm{wt} \% \mathrm{BS}$ waste in reference of research work on production of glass ceramic from industrial waste and immobilization of incineration ashes into $\operatorname{GCM}[12,13]$.

The prepared batch mixture are mixed for 30 minutes using mixing machine. The samples are then pressed at $90 \mathrm{MPa}$ in a mould of rectangular shape of $18 \mathrm{~mm} \times$ $18 \mathrm{~mm}$. The pressed samples were then sintered in a furnace with $2^{\circ} \mathrm{C} / \mathrm{min}$ heating rate at $800^{\circ} \mathrm{C}$.

Table 1. Ratios of BS to waste glass powder (wt \%)

\begin{tabular}{|c|c|}
\hline BS Powder [wt \%] & Waste Glass Powder [wt \%] \\
\hline 30 & 70 \\
\hline 40 & 60 \\
\hline 50 & 50 \\
\hline 60 & 40 \\
\hline 70 & 30 \\
\hline
\end{tabular}

The physical analyses of water absorption, bulk density and apparent porosity were determined according to ASTM C3739[14]. While, the determination of chemical resistance was carried out only on sintered samples from batch formulation of BS $30 \mathrm{wt} . \%$ and 70 wt. \% SLS waste glass. This is due to the optimum performance of low porosity, water absorption and high density during physical analyses. Chemical resistance determination were carried out according to MS ISO 10545-13:2001 Ceramic tiles-Determination of chemical resistance (ISO 10545-13:1995(E)[15]. In this test, samples were immersed in a low concentration test solution (Hydrochloric acid solution, 3\% (V/V), Citric acid solution, 100g/l, Hydrochloric acid solution, 18\% $(\mathrm{V} / \mathrm{V})$ and high concentration test solutions (Hydrochloric acid solution, 18\% (V/V), Lactic acid solution, 5\% (V/V), Potassium hydroxide solution, 100 $\mathrm{g} / \mathrm{l})$ for 12 days. Later, the test specimens were examined after day 5 and day 12 immersion at a distance of 25 to $30 \mathrm{~cm}$, with the naked eye of with spectacles if usually worn, for changes on the proper surface and noncut edge to determine the class of chemical resistance.

In order to evaluate the effect of the chemical attack on the microstructure of the GCM tiles, further observation on the surface and cross section area of samples that were immersed in potassium hydroxide solution (the most reactive solution) were conducted using scanning electron microscopy SEM EVO 50 Carl Zeiss SMT model operated at $20 \mathrm{kV}$.

\section{Results and Discussion}




\subsection{Porosity, Water Absorption and Bulk density}

Figure 1, 2 and 3 shows the apparent porosity, bulk density and water absorption of sintered glass composite with increased BS waste loading ranging from $30 \mathrm{wt} . \%$ to $70 \mathrm{wt} . \%$. It is observed that the porosity [\%] increases as the BS waste loading [\%] increases. A gradual increase in porosity (Fig. 1) is observed from BS waste loading of $30 \mathrm{wt} . \%$ up to $60 \mathrm{wt} \% \%$ followed by a drastic increase from $60 \mathrm{wt}$. $\%$ to $70 \mathrm{wt}$. $\%$. The lowest porosity value is given by $30 \mathrm{wt}$ \% BS waste loading with $70 \mathrm{wt}$. $\%$ of SLS waste glass sintered samples which is $2.20 \%$. The water absorption (Fig. 2) shows similar trend as the porosity. The minimum water absorption value is given by 30 wt. \% BS waste loading with 70 wt. \% of SLS waste glass sintered samples which is $1.17 \%$. Bulk density (Fig. 3) shows a decreasing trend with increasing waste percentage. 30 wt. \% BS waste loading with 70 wt. \% SLS waste glass sintered samples shows the highest bulk density of $1.88 \mathrm{~g} / \mathrm{cm}^{3}$. Based on these physical properties, sintered samples from batch formulation of BS $30 \mathrm{wt} . \%$ and $70 \mathrm{wt}$. \% SLS waste glass has shown optimum performance. Porosity contributes to the bulk density and water absorption characteristics of the sample.

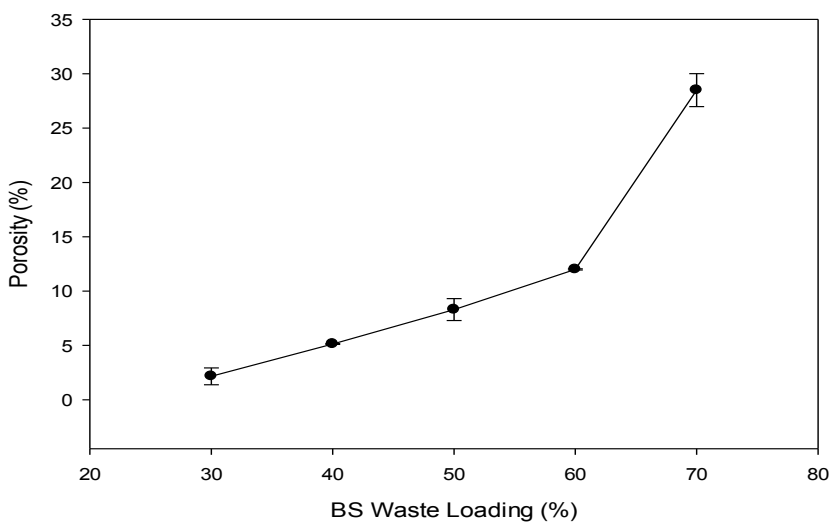

Fig. 1. Apparent Porosity (\%) of glass composite material according to BS waste loading (wt \%).

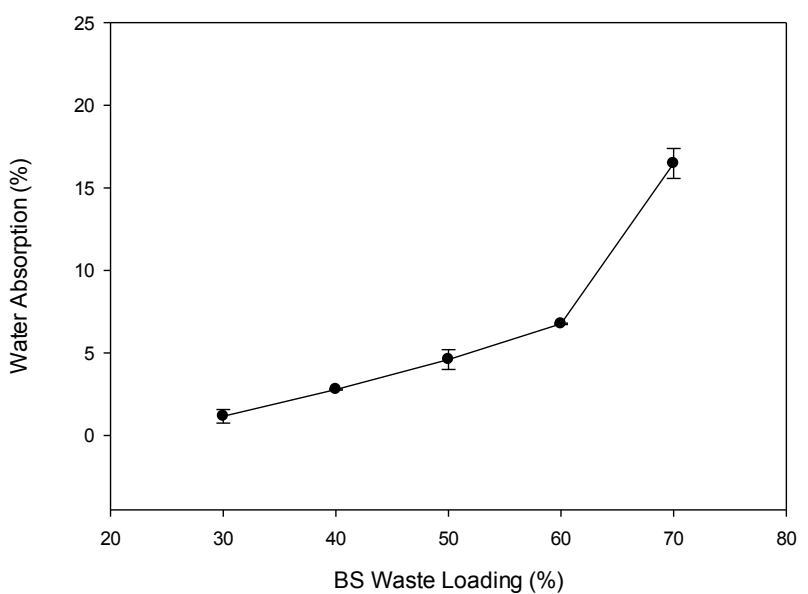

Fig. 2. Water Absorption (\%) of glass composite material according to BS waste loading (wt \%)

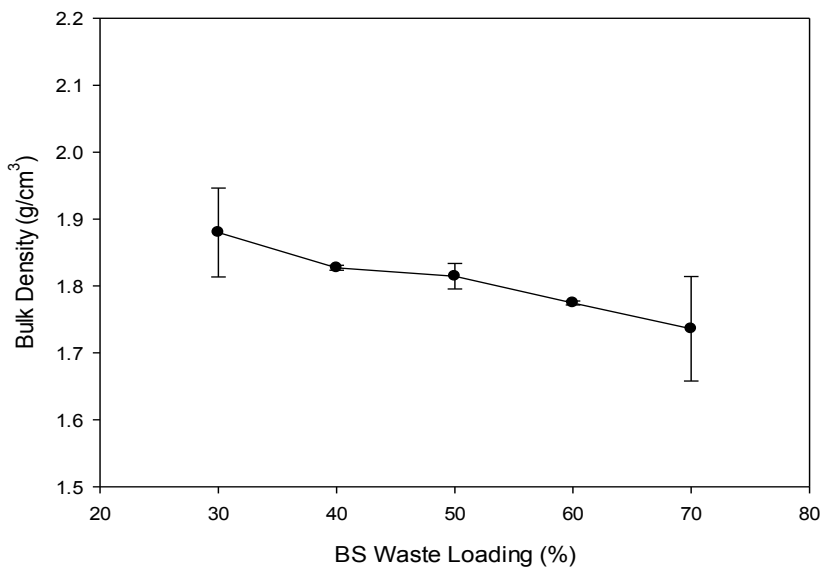

Fig. 3. Bulk density of glass composite material according to BS waste loading (wt \%)

\subsection{Chemical Resistance Classification}

Table 2 and Table 3 shows the chemical resistance class of GCM tiles made from batch formulation of BS $30 \mathrm{wt}$. $\%$ and $70 \mathrm{wt}$. \% SLS waste glass after the 5 days and 12 day immersion in the six different types of chemical solutions. Using naked eye in the daylight, the samples were observed using the correct procedure to determine the chemical effects on the samples. The results show that there are no visible effects on the GCM tiles after day 5 immersion. In contrast, severe effects on the GCM tiles were observed after 12 day immersion in low and high concentration chemical solution with a classification of ULC and UHC. Moreover, it was also observed that the GCM tiles are more prone to the acid solution compared to the alkali solution. This could be attributed to the properties of the SLS used in the GCM tiles making.

Table 2. Chemical Resistance Class of GCM tiles made from 30 wt. \% BS and 70 wt. \% SLS waste glass after day 5.

\begin{tabular}{|l|c|}
\hline Types of Low Concentration Solution & $\begin{array}{c}\text { Chemical } \\
\text { Resistance } \\
\text { Class }\end{array}$ \\
\hline Hydrochloric acid solution, 3\% (V/V) & ULA \\
\hline Citric acid solution, $100 \mathrm{~g} / 1$ & ULA \\
\hline $\begin{array}{l}\text { Potassium hydroxide solution, } \\
30 \mathrm{~g} / 1\end{array}$ & ULA \\
\hline Hydrochloric acid solution, $18 \%(\mathrm{~V} / \mathrm{V})$ & UHA \\
\hline $\begin{array}{l}\text { Lactic acid solution, } \\
5 \%(\mathrm{~V} / \mathrm{V})\end{array}$ & UHA \\
\hline $\begin{array}{l}\text { Potassium hydroxide solution, } \\
100 \mathrm{~g} / \mathrm{l}\end{array}$ & UHA \\
\hline
\end{tabular}

For low concentration test solution :

*Class ULA : No visible effect

*Class ULB : Visible effect on cut sides

*Class ULC : Visible effect on cut sides, non-cut sides and on the proper surface 
For high concentration test solution :

*Class UHA : No visible effect

*Class UHB : Visible effect on cut sides

*Class UHC : Visible effect on cut sides, non-cut sides and on the proper surface

Table 3. Chemical Resistance Class of GCM tiles made from BS and SLS Waste after day 12

\begin{tabular}{|l|c|}
\hline Types of High Concentration Solution & $\begin{array}{c}\text { Chemical } \\
\text { Resistance } \\
\text { Class }\end{array}$ \\
\hline Hydrochloric acid solution, $3 \%(\mathrm{~V} / \mathrm{V})$ & ULC \\
\hline Citric acid solution, $100 \mathrm{~g} / 1$ & ULC \\
\hline Potassium hydroxide solution, $30 \mathrm{~g} / \mathrm{l}$ & ULC \\
\hline Hydrochloric acid solution, $18 \%(\mathrm{~V} / \mathrm{V})$ & UHC \\
\hline Lactic acid solution, $5 \%(\mathrm{~V} / \mathrm{V})$ & UHC \\
\hline Potassium hydroxide solution, $100 \mathrm{~g} / 1$ & UHC \\
\hline
\end{tabular}

\subsection{Microstructural Analyses}

Samples from batch formulation of BS $30 \mathrm{wt} . \%$ and 70 wt. \% SLS waste glass and that were immersed in the most reactive chemical solution (potassium hydroxide solution of $100 \mathrm{~g} / \mathrm{l}$ ) were chosen to be further analysed using SEM. Figure 4 shows the SEM micrographs on the surface of the GCM tiles before the chemical resistance test. It is observed that the microstructure consist of 4 main features which is even dense surface, uneven dense surface, coarse feature, closed pores and open pores (figure 4 (a)). Chemical attack were observed after the samples immersed in high concentration test solutions. The chemical attack had affect the dense surface microstructure where a rough and crippled surface is observed at this region after the 12thd day immersion in the potassium hydroxide solution (Figure 4(b)). It is also observed that the open pores are larger with the edge of the pores is clearly visible.

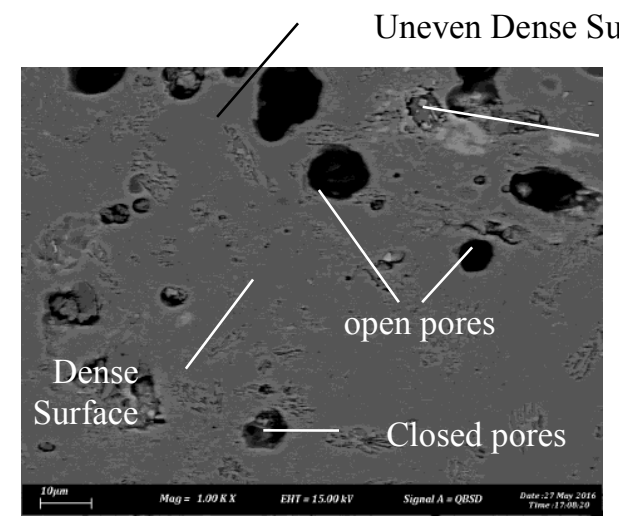

(a)

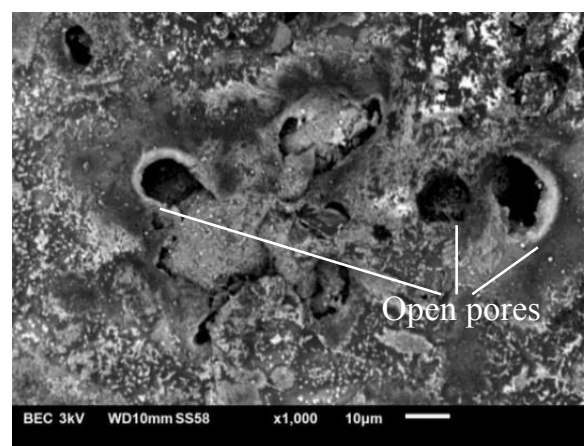

(b)

Fig. 4. SEM surface micrographs of GCM tiles made from 30 wt. \% BS and 70 wt. \% SLS waste glass a) before and b) after the chemical resistance tests.

Figure 5 shows the SEM micrographs on the cross sectional of the GCM tiles after the chemical resistance test. Chemical attack on dense surface, edge of closed pores were observed during SEM analyses as shown in figure 5(b). The dense surface that had been observed before the chemical test had become a rough surface due to the reaction of the high concentration test solution during the 12 immersion days. This is a similar observation as on the surface of the GCM tiles.

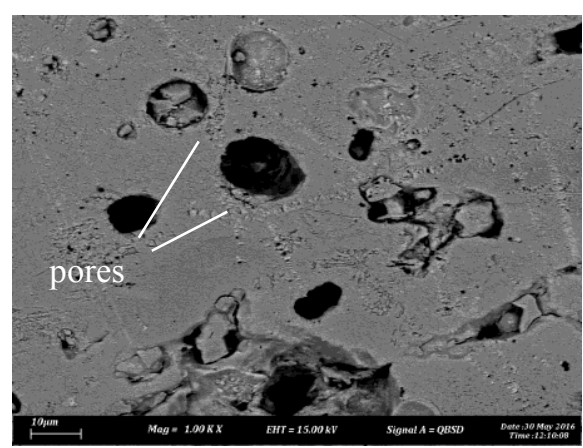

(a)

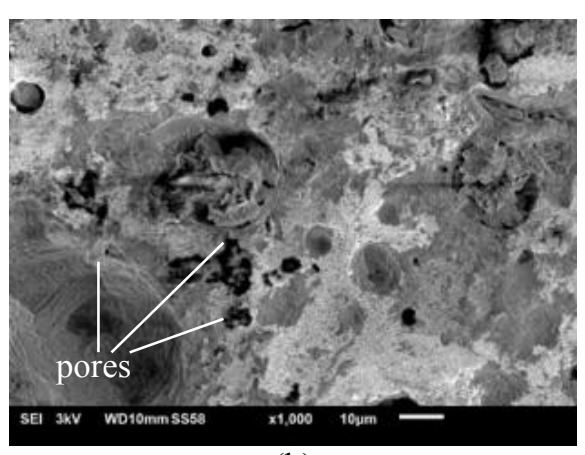

(b)

Fig. 5. SEM cross section micrographs of GCM tiles made from $30 \mathrm{wt}$ \% $\%$ BS and $70 \mathrm{wt}$ \% \% SLS waste glass before and after the chemical resistance tests.

\section{Conclusion}


Chemical resistance of sintered GCM tiles are related to its physical properties. GCM tiles made from 30wt. \% BS and 70 wt. \% transparent SLSG (with the lowest water absorption of $1.17 \%$ and porosity percentage of $2.2 \%$ with the highest bulk density of $1.88 \mathrm{~g} / \mathrm{cm}^{3}$ ) has shown good chemical resistance at early chemical immersion (5 days) to the test solution. However, the chemical resistance is weak upon increasing duration of immersion. The penetration of chemical in attacking the samples are related to the presence of pores. This is evident during the SEM analyses where the pores is observed to become more visible and larger due to the chemical reaction that take place. In consequence, further work on producing GCM tiles from BS and SLS waste glass should aimed to reduce the amount of porosity presence in the sintered GCM tiles.

We would like to acknowledge Ministry of Higher Education Malaysia for awarding the PRGS grant (Green Innovative Glass Ceramic: Towards Resources Efficiency In Tiles Industry) and support from members of Sustainable Materials for Green Technology (SM4GT) Research group of Advanced Manufacturing center, Faculty of Manufacturing Engineering, UTeM.

\section{References}

1. http://www.doe.gov.my/v2/files/legislation/pua0294y 2005.pdf (Enviromental Quality Scheduled Wastes Regulations 2005,Accessed on 18/10/2011

2. http://www.epa.gov/osw/inforesources/pubs/training/ incin.txt (Accessed on 2/8/2011)

3. S. Naganathan, H. AbdulRazak, S. Nadzriah, Preliminary Investigation of Incinerator Bottom Slag as Controlled Low-Strength Material, Int. Con. On Construction And Building Technology, 2008

4. www.doe.gov.my (Accessed on January 2012)

5. Z. A. Rashid, A.B. Alias, Aris, M.J, El-Harbawi, M, Rahman, N.A. and Som, A.M, Int. J. Environ. Eng., 2,139-158 (2010)

6. M. Shahnor Bani, Z. Abdul Rashid, K. Halim Ku Hamid, J. App. Sci.,11, 2358-2363, (2011)

7. H. Isa, Int. J. Phy. Sci., 6, 30, 6781 - 679, (2011)

8. S. Naganathan, H. Abdul Razak, S. Nadzriah Abdul Hamid, J. Mat. and Design, 33, 56-63, (2012)

9. T. Tarvornpanich, G.P. Souza, Use Of Soda-LimeSilica Waste Glass As An Alternative Flux In Traditional Ceramics, Int.l Con. on Geo. of Thai: Towards Sustainable Development and Sufficiency Economy,2007

10. M. Erol, S. Ku“c,u“kbayrak, A. Ersoy-Meric,boyu, J. Cer. Int., 35, 2609-2617(2009)

11. M. Eberstein, S. Reinsch, R. Müller, J. Deubener, W. A. Schiller, J. Eur.Cera. Soc., 29, 2469-2479(2009)

12. Bianka V. Mangutova, Emilija M. Fidancevska, Milosav I. Milosevski, Joerg H. Bossert, APTEFF, 35,1-280 (2004)

13. M. I. Ojovan, J. M. Juoi, W. E. Lee, J Pak. Mater. Soc., 2, 72-76(2008)

14. American Standard Testing Material (2006). Standard Test Method for Water Absorption, Bulk Density, Apparent porosity, and Apparent Specific
Gravity of Fired Whiteware Products, Ceramic Tiles, and Glass Tiles, West Conshohocken, U.S, ASTM C373-88.N.

15. Malaysian International Standard. Ceramic TilesPart 13: Determination of Chemical Resistance, Malaysia, MS ISO 10545-13:2001 (ISO 1054513:1995 (E)). 